\title{
Intercultural pedagogies: experiencing the kungfu teaching methods at the Shaolin Temple
}

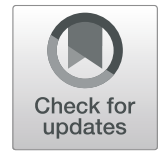

\author{
Marta Nešković $(\mathbb{D}$
}

Received: 8 April 2020 / Accepted: 5 November 2020 / Published online: 19 November 2020 (C) The Author(s). 2020 Open Access This article is licensed under a Creative Commons Attribution 4.0 International License, which permits use, sharing, adaptation, distribution and reproduction in any medium or format, as long as you give appropriate credit to the original author(s) and the source, provide a link to the Creative Commons licence, and indicate if changes were made. The images or other third party material in this article are included in the article's Creative Commons licence, unless indicated otherwise in a credit line to the material. If material is not included in the article's Creative Commons licence and your intended use is not permitted by statutory regulation or exceeds the permitted use, you will need to obtain permission directly from the copyright holder. To view a copy of this licence, visit http://creativecommons.org/licenses/by/4.0/.

\begin{abstract}
The Shaolin Temple is a unique religious institution in China. It is the most renowned temple of Chan Buddhism and, at the same time, a famed site of intensive cultivation of traditional kungfu. Besides running the kungfu program for selected Chinese youth, the Temple offers a program for foreign students interested in training kungfu in its authentic cultural setting. Founded on anthropology of education, the theories of embodiment, and the theory of practice, our research project is focused on the relationship between the Shaolin kungfu and Chan Buddhism. The aim of this paper is to describe the students' perceptions of the Shaolin kungfu teaching methods through the analyses of their narrated personal experiences. The research is based on our 16 months of fieldwork in the Temple, which comprised a full participation in the training program as well as the formal and informal interviews and the group discussions with the students. The paper presents the students' perceptions of the Shaolin masters' training methods, the main kungfu principles and their sources, as well as the differences between the training approaches in the Temple and in their home countries. In addition, the study brings forth the concept of intercultural martial arts pedagogies and its application in a representative Chan Buddhist setting.
\end{abstract}

\footnotetext{
M. Nešković $(\bowtie)$

Department of Ethnology and Anthropology, Faculty of Philosophy, University of Belgrade, 18-20 Čika Ljubina Street, Belgrade 11000, Serbia

e-mail: martaneskovic@outlook.com
} 
Keywords Shaolin Temple · Chan Buddhism - Anthropology of embodied learning · Kungfu · Teaching methods · Martial arts pedagogies · Foreign students · China

\section{Introduction $^{1}$}

\section{Research aim}

The aim of this paper is to develop an understanding of foreign students' perceptions of the traditional educational methods of the present-day Shaolin Temple. This anthropological analysis is based on the exploration of the students' personal experiences of the transfer of kungfu knowledge and skills during their stay in the Temple. We shall thus analyze the students' impressions on the Shaolin masters' training methods, the main kungfu principles and their sources (Chan Buddhism and the wider Chinese martial arts traditions), the space for imitation and creativity as well as the differences between the training approaches in the Temple and in their home countries. It will be further shown how the integration of the diverse theoretical approaches, joined with the personal experience of thick participation (Samudra 2008) and the analyses of the interviews with students, has brought forth the concept of intercultural martial arts pedagogies and its application in an exemplary Chan Buddhist setting. A more general goal of our research project is to understand the changes in the body-mind relationship of the Shaolin kungfu practitioners, from one level of the martial arts performance to the next, brought about by the Temple's educational process both in its formal and informal aspects.

The Shaolin kungfu is here viewed through both its spiritual content and its own esthetics of performance. The Shaolin culture represents a body of knowledge synthesized through its different elements the most prominent of which are the Chan Buddhist practices (meditation and chanting), the Shaolin kungfu, and the traditional Chinese medicine. The Shaolin kungfu is here understood as a martial artwork, which communicates the cultural heritage of Chan Buddhism through specific approach to lifestyle, training and performative skills, therefore making the Shaolin kungfu representative of the Chan philosophy. It is believed in the monastic community that the Shaolin kungfu embodies the Shaolin culture, and that it is used for self-cultivation purposes as well as for service to society in the ways that have changed over time - from real life fighting for military purposes in the past to artistic performance of the warrior monks at present.

\section{Relevant literature on anthropology of martial arts pedagogies}

Contemporary martial arts studies make a diversified, heterogeneous and multidisciplinary field without a unifying theoretical approach (Bowman 2019). Such state of the art makes the field all the more interesting since it allows empirical explorations in different directions and opens space for new theoretical contributions.

\footnotetext{
${ }^{1}$ This research is part of the project No. 177017 of the Ministry of Education, Science and Technological Development of the Republic of Serbia.
} 
Three streams of literature on martial arts pedagogies nested in closer or further proximity of this research have been identified. The first stream involves more general theoretical studies of martial arts and their relationships with sports and transnational presence, the second one entails investigations in which martial arts pedagogies or their elements are revealed in a variety of cultural settings, while the third one comprises works that are devoted to the sources of the Shaolin kungfu moral and practical pedagogies.

Among the early anthropological works within the first stream of studies related to the contemporary Asian body practice is Brownell's book Training the Body for China (1995), in which the contrasts between the Chinese and Western body cultures are analyzed. More recent studies, such as those included in the edited volume Martial Arts as Embodied Knowledge (Farrer and Whalen-Bridge 2011), encompass different approaches to the Asian martial arts, i.e., the martial arts as the embodiment of fantasy, culturally grounded forms of self-cultivation, and a continual process of identity formation. This ethnographic material describes the ways in which social bodies are trained via martial arts and how some martial arts transform through their transnational spread. The overarching stance in all these studies, both of traditional and modern body disciplines, is that more attention should be paid to theoretical aspects of the disciplines and to the national and transnational networks they belong to (Besnier and Brownell 2012).

Within the second stream of literature, the Bourdieu's concept of habitus (1972) seems to be crucial in anthropological research that entails researcher's selfinvolvement and thick description, especially when analyzing martial arts as having effects on self-perception and inducing spiritual turns. To a large extent, the present standard for scholarly research and writing on martial arts has been set by Wacquant's book Body and Soul: Notebooks of an Apprentice Boxer (2004), which is an extraordinary ethnographic voyage into the world of a Chicago inner-city boxing gym. This thick anthropological account shows that transmission of boxing knowledge is a complex socio-cultural phenomenon, with numerous actors and their relationships added to the specific training and fighting strategies and techniques.

Other relevant studies within the second stream are related to the Asian martial arts practice in different cultural contexts. Jennings et al. (2010) explore the ways in which Wing Chun Kungfu functions as a secular religious practice for association's core members in England as well as how Wing Chun habitus is developed over time. Then, Channon (2012) deals with how British men, drawing upon the imagined uniqueness of their martial arts, use them to construct a sense of moral superiority over other men. Favoring features of the Eastern martial arts, they reject what they believe to be the mainstream sporting Western masculinity, and point at the role that the alternative visions of corporal culture can play in men's perceptions of gender. Johnson (2017) gives the useful insights about the possibility of stratifying martial arts pedagogical process (from musul/technique to muye/artistry and finally to mudo/ way). ${ }^{2}$ Writing about the taekwando practice, the author gives an example of how

\footnotetext{
${ }^{2}$ This mode of stratifying a pedagogical process and its outcomes differs from the general one offered by Dreyfus and Dreyfus (1986), which names the following levels: novice, beginner, competent, proficient, advanced and expert.
} 
such a stratified pedagogy can express the way of learning martial arts knowledge and skills and, more importantly, of adapting and then adopting them into daily life routines.

Also within the second stream of literature, Mullis (2013) discusses the integration of movement, the concept of fluidity, and the mind-body relation. In his view, the somatic integration assumes that a practitioner learns to increasingly appreciate the feeling of mental and physical integration. Analyzing Brazilian jiu-jitsu, Kohoutkova et al. (2018) offer the insights for deeper understanding of the flow in body movement. Different definitions of the flow, from a skill to a state, are of major importance for an integral understanding of the learning process of a martial artist.

Theoretical studies of religious body movement in different cultures, within the second stream, represent important comparative literature for research of the Chan Buddhist kungfu. Among them are the studies of kalaripayattu, in India (Mcdonald 2003), and of capoeira angola, in Brazil (Höfling 2006), which speak about how traditional religious martial arts practice has been reinterpreted for the purpose of building national and regional identities in various complex socio-political environments.

Within the third stream of literature, Shahar's book The Shaolin Monastery (2008) appears as a sound study of the history of Chinese martial arts as developed through centuries in the religious setting of the Shaolin Temple. Based on the written sources from the Temple's archives, it serves as the grounded framework for understanding the wider religious context but also the development of the specific martial arts, both of which help one understand the habitus of the Shaolin kungfu masters. The book written by Abbot Shi Yongxin, Shaolin Kungfu (2014), first in Chinese and recently in English, represents the contemporary formal stance on the Shaolin kungfu as an embodiment of the religious, philosophical and ethical values of Chan Buddhism cultivated in the long history of the Shaolin Temple.

All these studies show two key points. First, there is no unifying theoretical framework specifically related neither to martial arts nor to the relationship between the Eastern and Western martial arts (Besnier and Brownell 2012; Bowman 2019). Second, theoretically framed studies of the East Asian martial arts are relatively scarce, and only a few of them treat more than one theoretical position we consider crucial for this area of study, being intercultural pedagogies, embodiment, and habitus.

\section{Theoretical and methodological framework}

\section{Theoretical framework}

The study presented here focuses on the martial arts pedagogies in an intercultural context, namely, on the experiences of the foreign students learning kungfu in the Shaolin Temple, as one of the principal sites of its origin. The empirical explorations of this topic were based on the theoretical framework made to help us integrate several conceptual stances. 
The first stance was based on the theories created within anthropology of education that encompass thematic concerns such as: the necessity for socio-cultural contextualization of the educational process and its analysis, the relations of education to culturally phrased stages of life cycle, and the nature of intercultural understanding and learning (Spindler 2000; Bloome et al. 2018). The theories of embodied learning further support the study of acquiring knowledge and skills in specific cultural contexts (Marchand 2018). All of these themes and concepts appear in the study of the kungfu training program at the Shaolin Temple. This particular contribution is devoted to the degree of understanding and internalization of the Temple's educational methods and principles through a study of the Shaolin kungfu.

Special attention is paid to intercultural education, which here entails an encounter between the Eastern and Western martial arts traditions, i.e., the Chinese teachers of kungfu and their students. With its approach to deep structures of socialization, schooling, and intercultural understanding, anthropology of education (Bloome et al. 2018) is able to provide a broader context of cultural processes across the Shaolin Temple's institutions that promote the Shaolin kungfu both in local and global settings.

The second conceptual stance comes out of the theories of embodiment. Csordas's cultural phenomenology of embodiment postulates that the body is not an object but a subject of culture. In the core of this view is the attitude that the human activity constitutes the physical being, i.e., the lived body, as it is perceived by the humans themselves through their senses, feelings and experiences. This paradigm allows one to overcome the ontological dualities of subject-object and body-spirit (Csordas 1990, 1994, 2002). Another related concept is that of dynamic embodiment (Williams 1982, 1991; Farnell 1994, 1999, 2012; Varela 2003), which assumes that the human being in motion is a subject of action. Our aim is to understand how the dynamic embodiment of the Shaolin kungfu concepts is expressed through the practitioners' speech from the body. This perspective lets us conceptualize the body, localize the self of the Shaolin kungfu practitioners, and investigate the processes that occur during and as the consequence of the practice. We thus treat the body as a resource for action, which unites the experience of the outer and inner subjective universes of the individual. This stance also carries an important methodological implication, which is that anthropologists should use their own bodies to experience the transmission of kungfu knowledge, and thus understand and inform others about the socio-cultural processes related to this specific mode of embodiment.

The third conceptual stance is based on the theory of practice, which opens space for exploration of the deep structures and dynamics of the habitus of each kungfu practitioner at the Shaolin Temple (Bourdieu 1972, 2002; Wacquant 2004; Delamont and Stephens 2008). The concept of habitus ${ }^{3}$ was constructed from the

\footnotetext{
${ }^{3}$ The study uses the concept of habitus as described by Delamont and Stephens (2008, 59), who state: "The habitus is both a state of mind and a bodily state of being. At an individual level, person's biology and biography gives him or her a unique habitus. Simultaneously, however, that person is also shaped by the collective history of any group(s) to which he or she belongs. Thus, education and occupational socialization contribute to the individual habitus".
} 
embodied cultures of the martial arts students. They acquired an intercultural experience of becoming subjects of the pedagogies of the Temple's masters, who were assigned the task of adapting and transferring the traditional Shaolin kungfu knowledge and skills to the practitioners coming from all around the world.

\section{Research methodology}

Our anthropological fieldwork related to the paper lasted 16 months, from April 2018 to August 2019. It was primarily based on the qualitative anthropological methods (Bernard 2006; Vučinić Nešković 2013), which included different types of observation, interviews, and small group discussions. The enrollment in the Shaolin Temple's educational program for foreign students and the attendance of the kungfu classes with them throughout the whole research period allowed us to apply the full participant approach. The interviews we conducted were formal (scheduled and recorded) and informal (conducted ad hoc and not recorded). The formal interviews, with 20 selected students, were conducted according to a standardized structured questionnaire. The informal interviews were often adapted to each respondent's profile. Over that period, we had a chance to meet more than 100 students participating in the students' kungfu program of the Temple.

The questionnaire we designed for the research had the following characteristics. The introductory part focused on the biographical data of a student but also on a short history of his/her practicing sports and martial arts. The questionnaire aimed to gather information about the student's perception of the kungfu education in the Shaolin Temple. The questions targeted the master-student relationship, the teaching approach of the masters, the process of learning that the student experienced while at the Temple, and his/her insight into the traditional sources of the Shaolin kungfu. They were adjusted to enable us to acquire the comparable qualitative data specific for the individual and related to his/her unique experience in the Temple.

The analysis of the answers to the formal interviews has been based on our own experiences, observations and intuitive impressions as well as on the informal interviews and discussions with all the students who we had the chance to meet and communicate with during the fieldwork.

\section{Analysis of the research results}

Characteristics of the studied group of foreign students

The Shaolin Temple kungfu program for foreign students is open to kungfu practitioners and fans of the Shaolin culture regardless of their country of origin, gender, age, physical readiness, religious and cultural affiliations, professional orientation, reasons for coming, and desired length of stay.

The students attending the kungfu program come from all around the world. Our research sample included 20 students, which were chosen to reflect the characteristics of the student body that joined the program in the period while we were 
there. A great majority of the respondents came from Europe (14), while India (2), Russia (2), the USA (1), and French Polynesia (1) were also represented.

The age span of the respondents was between 17 and 51. They were predominantly male (14), aged between 20 and 30, and in the physical condition suitable for recreational martial arts training. The female respondents, aged between 20 and 40, were at very different levels of physical readiness and martial arts experience. A quarter of the respondents had started families and had children. As for the religious affiliation, five of the students declared themselves as Buddhists, two as Muslims, another two as Roman Catholics, and six as having no religion. Five students said that they had self-defined spiritual beliefs.

Seven of the respondents were professionally oriented and were supporting themselves with activities related to martial arts, dance or medicine-related practices (traditional Chinese medicine with acupuncture or physiotherapy). Five of them had kungfu students in their countries and two founded their own kungfu schools. Regarding their previous involvement with kungfu, seven students had more than 5 years of experience, seven practiced kungfu between one and 5 years, four trained less than a year, and two had no experience before coming to the Shaolin Temple.

Almost a half of our respondents had experience with other martial arts, such as karate and judo, before deciding to learn kungfu. Other practices they mentioned were yoga, tap dance, football, basketball, running, fitness and skating. It may be noted that even the respondents who chose to devote their professional life to kungfu, conceptualized it as a form of self-cultivation combined with teaching others. Not even one of them pursued a career in martial arts competitions or as a martial arts performer. The ones who had jobs related to kungfu started practicing at a rather young age and those who started their kungfu journey somewhat later perceived the practice as more than just a leisure, mainly as a tool for selfcultivation and self-discovery.

The students were accommodated in the Shaolin Disciples' Home, in the village of Wangzhigou, near the Shaolin Temple, and they were taken care of by the Temple's Office of Foreign Affairs. They lived together in a common dormitory, where they shared four-bed rooms and ate the same food, and participated in the Temple's events as a group. Soft and willing collisions of different cultures within the group, where the exchange of experiences between the new and old students was regular, nurtured different ways of understanding the Shaolin kungfu, the Temple life with its rules and routines, the Temple's education as well as the comprehension of the relationships the students could and were permitted to have with the monastic community and the sacred space.

\section{Kungfu training program at the Shaolin Temple}

The Shaolin Temple offers to the international community different approaches to understanding the Shaolin cultural heritage and Chan practice as a way of life. This is made possible through the cultural program open to foreign students, for which a master participating in its organization says: "Without age, racial, cultural or social discrimination, it aims to bring optimism, clarity of mind, empathy, 
compassion and a little bit of wisdom to interested individuals". The program offers the Shaolin daily kungfu trainings but also an introduction to the Shaolin culture through Chan meditation, traditional medicine, calligraphy, Chan archery, and game of Go. How does it work in practice? The martial arts trainings are organized twice a day ( $2 \mathrm{~h}$ in the morning and two in the afternoon) while the other activities are organized on request and in accordance with the number of interested parties (meditation, traditional medicine and calligraphy) or during special events throughout the year (Chan archery and game of Go).

Since most of the foreigners do not speak Chinese and most of the masters do not speak English, translation is organized for the first few basic lessons. If, however, the students want to deepen their knowledge in any of these fields and seriously devote themselves to study of any or all aspects of the Shaolin culture, it is necessary that they not only communicate with the masters in Chinese but also to stay for a longer period of time. The result is that during most of the year there are only regular kungfu classes while in certain periods, when there is at least a small group of students who wish to learn about Chan meditation, Buddhist culture or traditional medicine, a few introductory classes are organized. The latter classes usually take place once a week, on weekends, when there are no kungfu trainings. This kind of schedule leaves plenty of spare time to students, which they usually spend enjoying the scenery of the Shaolin Temple and the nearby mountains or socializing with fellow students in the village of Wangzhigou or in the nearby town of Dengfeng.

At the time of our interviews and discussions with the students, we had three masters responsible for the trainings. Two of them were the main masters and one would occasionally help, when the other two were not able to teach. After the spring of 2019, the third master stopped being affiliated with the students' group and we got two new associate masters, both of whom had spent years teaching in foreign countries. The answers to our questionnaire describe the students' impressions of the trainings held by our two main masters during the period from April to November 2018. The two masters changed between themselves on a weekly or monthly basis. Beside this job, the masters have other obligations in the Shaolin Temple due to their religious affiliation with the Temple and as part of the warrior monks' teams. ${ }^{4}$ The educational program for the students as well as their participation in the Temple's events and the interactions with the monastic community is regulated by the Temple's Office of Foreign Affairs.

It is a regularity that the students who stay in the Shaolin Temple for a longer time help the newcomers with their daily needs, starting from turning on the washing machine in the Disciples' Home to communicating with the masters. When a newcomer who has never trained the Shaolin kungfu comes to the training, the

\footnotetext{
${ }^{4}$ In the paper, the term warrior monks (武僧 - wǔsēng) refers to the male members of the monastic community who come to the Temple for the purpose of practicing kungfu, live in the warrior monks community (武僧团 - wǔsēng tuán) in the Temple, and have as their primary obligation practicing and representing the Shaolin Kungfu heritage inside the Temple as well as all over the world, as performers and masters. The warrior monks can be but are not necessarily ordained Buddhist monks (和尚 héshàng). They start their religious path in the Temple as lay Buddhists and disciples and can choose after the age of 20 whether they want to follow the path of ordained Buddhist monks or not.
} 
master asks a more experienced student to teach him/her a particular chosen form (usually 五步拳 - wǔbùquán or连环拳 - liánhuánquán). The master starts to teach a student when he/she memorizes the movements. The teaching is mainly based on correcting the basic postures, explaining the movements and movement transitions, and trying to introduce very slowly the fact that he/she should use power when practicing the form. The masters often repeat that every time we practice a form we should really practice it, using all our capacities instead of just repeating the movements. They stress that learning a form is not the same as practicing a form. ${ }^{5}$

During our whole stay at the Shaolin Temple, there was always at least one student in the group whose knowledge of Chinese was sufficiently high to translate the masters' instructions. Some of the masters speak English to a certain extent after some years spent abroad teaching kungfu. One of our masters who almost never used English had developed a perfectly understandable body language, which made the translation unnecessary. However, our own experience tells that understanding verbal language does not only enable communication with the master but creates a completely different atmosphere for the student. The perspective of the Shaolin cultural context is quite different when one, even partly, understands Chinese, and thus can understand what is said in his/her surroundings and verbally express himself/herself. The students who do not speak Chinese often misunderstand the details of what is said or going on around them during the trainings, which can spoil the class discipline and atmosphere.

Students' perceptions and experiences of learning kungfu at the Shaolin Temple

\section{Learning from different Shaolin kungfu masters}

The basic structure of the foreign students' training is always the same - in the first hour, they practice the basics of kungfu (基本功 - jūběngōng) ${ }^{6}$ and in the second hour a choice is made between forms, strength, jumping or particular body movements that are supposed to make the body more fluid and are part of more complex forms (usually animal forms).

The students preferred to have more than one master because that allowed them to experience different approaches to teaching and different aspects of training. They described our masters and their approaches in the following way:

- Master 1: more structural, very hard on students, focuses on power, prolongs the time intended for training the basics (2), more extreme and pushing, if you do something bad he will get mad, and strict (2). However, the following

\footnotetext{
${ }^{5}$ In our understanding of the masters, the following may be said about this difference. Learning a form refers to memorizing the movements while practicing the form actually means repeating the movements over and over again with the aim of appropriating them with the body, i.e., making them natural for it, and thus allowing us to use the form as an acquired technique. With practicing the forms, we refine the body into a skilled movement tool enabling us to express our physical potential.

${ }^{6}$ Throughout the text, we use the term 基本功 - jüběngōng in its varied translations, namely, as the basics of kungfu, the kungfu fundamentals, or just the basics.
} 
remarks also came up for the same master: not hard on us, and wants to teach everyone.

- Master 2: concentrates on practicing forms $(2)^{7}$ and the basics - especially on the stances and on getting them low enough, concentrates on the group more then on individuals, friendly and encouraging with the beginners, repeats a lot the same basic principles, old way - will teach you only if you are really interested, rarely teaches new forms, tells us to use power, focuses on weaknesses, and talks more.

Our respondents remarked that different masters interacted with them in different ways. Some of their comments were: "Every master has his own style, but all point in the same direction"; "Each master has a different approach depending on his personality and experience"; "Different journeys, same destination"; "During the training, the masters are very strict, otherwise free and relaxed". The masters were said to ask for: discipline, strength/power, endurance, and development of the feeling of kungfu movement.

When talking about the discipline of training in a class, in general, the students noted that the masters' strictness was directed towards the group more than towards the individuals. Even though it was mentioned that every master had his own approach to teaching, the firmness of their attitude was inevitably present with each of them. The masters were considered strict by a majority of students but not as strict as with the Chinese students of kungfu in the Shaolin Temple. Even the Chinese students who were training with the foreign group were treated more strictly compared to the foreigners. The training structure had to be respected by all the students but the masters would accommodate the training with regard to the physical capacities of the majority of participants. One of the students said that the approach towards an individual trainee was more lighthearted and that it could not get too serious because "we are foreigners and adults after all and they cannot treat us the same as the Chinese children".

\section{Perceptions of the Shaolin kungfu teaching method}

A number of our questions posed to the students focused on the major characteristics of the Shaolin kungfu training method. The students were repeatedly reminded by the masters that speed and flexibility were the most important qualities of body and movement that enabled progress. The critique they often received was that they were lazy and lacking spirit, and that, consequently, their kungfu forms did not express power. We also noticed that the critique was about the students going too fast and not finishing the movements, and not knowing how to follow the kungfu principles of body movement (hips together with shoulders, knees with elbows and hands with feet). A great majority of students attending the classes were respectful towards the masters and the discipline they imposed. They tended to take the classes seriously by coming on time, following the master's instructions, and

\footnotetext{
${ }^{7}$ It should be noted that throughout the analysis. The number of respondents who shared the same stance will be given in parentheses only if it exceeds one.
} 
maintaining a self-disciplined atmosphere (no talking, no disturbing the others, not resting before the break time, etc.).

Some of the characteristics of the training recognized by the students were: hard work, repetition, relaxed strength, "watch and repeat until you understand", "when practicing, don't rush and do every movement from the beginning to the end", "as slow as you need ... but correct" (4), and "stance perfection". However, one of the characteristics of the Shaolin kungfu trainings, recognized mostly by the more experienced students, was the insistence on repetition. The beginners tended to believe that the master's instruction to repeat the same form for many days, weeks and months was a sort of punishment or at least a sign that they were not doing well in the training. Only after a lengthier period of the Shaolin kungfu practice, the students did realize that the crucial method of developing the kungfu skills is repetition. A relatively small number of students (up to 10 among a hundred we met during the fieldwork) actually maintained the motivation to repeat the kungfu forms every day with equal enthusiasm.

The students felt that the qualities one needed to develop in order to progress during the trainings were: patience, body memory, discipline (5), consistency (2), dedication, "to have a structure when you train", "to relax when you perform ... to release the tension", and "to know your motivation and have intensity and spirit in every movement". They mentioned that the trainings were mostly focused on the group and that they did not receive much individual attention. Some were bothered by that and felt the masters neglected them but a majority understood it as a characteristic of the Chinese traditional education. The masters explained the situation simply by a lack of time. Even though the students did perceive the masters' approach to teaching to be "traditional", which, among other things, meant that they should demonstrate deep devotion to the training, the problem of time limitation was usually neglected. No matter how much a student would be devoted to developing his/her kungfu skills during training, there was not much the master could do except to offer the student advice on the necessary corrections. Once the master has done his part, the student should develop the skills himself/herself, and that requires time. However, at least half of the students always seemed to expect that the master somehow possessed a key to fast-forward in acquiring the Shaolin kungfu skills, enabling him to teach the students an amazing skill in a short time. Since that did not happen, some students became aware of the requirements of the process of acquiring the skills and the importance of patience while a few others departed disappointed. After all, one must admit that asking for patience an excited student whose Shaolin dream finally started to become real was a difficult task.

Here are some details about the kungfu trainings that the students put forward. The words that were mostly repeated by the masters when they were correcting them were "power" (7) and "lower" (5). ${ }^{8}$ The principles that the students recognized as integrated into the trainings were: repetition (6), respect towards the master and the Shaolin culture (2), altruism, humbleness, hard work, devotion to the

\footnotetext{
${ }^{8}$ The word "power" referred to putting in more strength into the movements, and the word "lower" was related to putting the body closer to the ground when taking the basic stances and making the movements.
} 
master and self-discipline, pushing to the boundaries, comparison with the other students as well as with the masters' movements and the warrior monks' performances, comparison between their current and prior performances (they were encouraged to make videos of themselves during free time). One of the students said that the masters transmitted the principles of Shaolin kungfu with their voice and demeanor as well as through their movement demonstrations. He explained: "The masters convey the principles to the students by how they carry themselves ... they are inspiring by themselves".

\section{Assessment of the attained levels of kungfu skills}

Students at the Shaolin Temple often discuss each other's level of kungfu skills development. However, these discussions do not have a formal foundation. The reason is the fact that no formal classification of the skills existed during our fieldwork. The Temple established the first standardization of the Shaolin kungfu theory and practice at the end of 2019, when they introduced the following 18 levels: nine duans and nine pins (where the pins are the degrees of mastery following the ninth duan). ${ }^{9}$

Since the Shaolin kungfu is a practice encompassing a variety of physical skills, the students always compare each other's kungfu foundations (基本功 - jīběngōng), which comprise the main stances and footwork, jumps, fist and foot attack/ defense techniques as well as the basic stretching and physical conditioning. The masters also evaluate the students' performances through the appropriateness of their kungfu foundations. They permanently give students advice on how to correct their basics and acquire further skills (strength, speed and precision). All the students train together while every student is also approached as an individual in need of perfecting his/her skills. Since the concept of kungfu foundations is quite wide, each student would say that he/she has the preferred aspects of the skills or the ones in which he/she feels more comfortable, and the other aspects in which he/she feels weaker. After acquiring the basic kungfu skills, a student would practice different Shaolin kungfu traditional forms (套路 - tàolù). The form is a unit of kungfu practice, which is actually a set of attack/defense techniques. In any case, all the students coming to the Shaolin Temple would always have something to correct or something new to learn, and will therefore always remain students.

\section{Principles of the Shaolin kungfu and their relationship with Chan Buddhism and the Chinese martial arts traditions}

The students were asked whether they believed the Shaolin kungfu principles were specific to that particular practice or they came from a martial arts tradition and/or a Buddhist tradition. Twelve of them believe that these principles are based on the principles of both a wider Buddhist teaching and martial arts tradition. Among the

\footnotetext{
${ }^{9}$ There ia a number of categorizations of the level of knowledge and skills attained. Among them is the one given by Dreyfus and Dreyfus (1986), mentioned in footnote 2. However, such classifications cannot be applied directly to the traditional Chinese system of kungfu skills in the Shaolin Temple.
} 
other eight students, two believe that the Shaolin kungfu principles came from the Chan Buddhist teachings, another two believe that they are part of a wider Chinese martial arts tradition, and the remaining four did not have an answer to the question. Some students, which recognize the links with the martial arts tradition, mentioned that the Shaolin Temple was collecting different martial arts knowledge from all around China, safeguarding and developing it over time. This is how they explain why it is said that all the Chinese martial arts come from Shaolin, even though parts of that heritage originated in other regions.

However, six out of the above mentioned 12 students considered that there were concepts that were specific to the Shaolin kungfu, "otherwise there wouldn't be a thing such as the Shaolin kungfu". Two of them underlined that the uniqueness of the Shaolin kungfu in fact came from the specific relationship between martial arts and Chan Buddhism. The integration of the Buddhist principles with the martial arts principles is what actually defines the main feature of the Shaolin kungfu and what makes the character of this practice. This stance is best illustrated by a student who said: "The Buddhist teachings must be part of the Shaolin kungfu teaching so that it can be better and more perfect".

The students understand the Chan Buddhist contribution to the kungfu practice to be mostly concentrated around this religious practice offering self-cultivation, a way to learn how to control the mind and stay peaceful, and a way to improve concentration. One student noted that "respect, discipline and spirit" were the Buddhist principles that were unavoidably integrated into the Shaolin kungfu. Chan Buddhism was mostly narrowed down to the practice of meditation and its contribution was mentioned in that sense. The students also thought that meditation was necessary for the attainment of body flow, ${ }^{10}$ which was perceived as one of the principal determinants of the higher level of kungfu skills. Even a beginner, with no more than 3 weeks of practice in the Shaolin Temple, had the feeling that acquiring "the flow required a longer period of practice so that the body could get accustomed and become, for example, flexible enough". The body flow is mostly understood by the students as something that comes out of "an ultimate relaxation" and requires the integration of a calm mind and a prepared body. Some students think that a real life application of the kungfu practice is necessary for us "to get the flow" of movement. A student with 10 years of experience in karate and a few years of experience in kungfu said that he had never seen anyone having a perfect flow. Two students made the connection between the kungfu practice and the Chan practice in the following way: "I need meditation to improve my concentration ... no concentration means we cannot think about the movements and the power cannot be appropriate", and "I need spiritual calm and harmony, physical exercise and qigong". An adequate summary of what everybody agrees upon is that kungfu requires perseverance and a lot of practice - the students agree with the Shaolin masters when they say: "One minute on stage requires ten years of hard work and effort backstage".

\footnotetext{
${ }^{10}$ On the importance of the concept of body flow, see the research of Kohoutkova et al. (2018) on jiujitsu in Brazil.
} 
Regarding the origin and development of the Shaolin kungfu principles, the students have identified two main influences. Most of them presume that the development of the principles has been characterized by a synergy of the Chinese martial arts tradition and the Chan Buddhist teachings. These influences together, resulted in creating a unique practice that can be interpreted and used as a martial art, selfcultivation practice and/or traditional cultural heritage.

\section{Differences between the trainings at the Shaolin Temple and at home}

The Western students who came to train at the Shaolin Temple characterized its education to be traditional as opposed to modern Western sport practices, martial arts, and fitness trainings. The students from Europe noticed that in their countries the major factor that determined the level of teachers and students' involvement was the financial arrangement they had agreed upon. If the trainer is paid, he/she will devote attention to the student, but if he/she is not fully involved, the student will leave and the trainer will lose the customer. If the student does not come to the training, he/she will waste the money given to the trainer and all the money previously invested in the trainings might become wasted. This is, of course, a simplification, but it stresses the economic value involved, which, in view of our respondents, is prioritized in the modern West.

It is important to recollect the views of two Indian students, who were more familiar with another traditional Eastern way of teaching martial arts. Both of them had experience in training with Indian martial arts masters. One of them practiced in his older relative's (perieppa) house for two and a half years. Perieppa was his grandmother's brother who was a master of kalaripayattu, a traditional Indian martial art. Even though the boy liked kalaripayattu very much and trained in the master's house with other younger masters, he was never actually trained by the master and never even saw him practice. The student explained that the Indian masters do not easily accept new apprentices. The other Indian student had a master of kungfu in his hometown in India with whom he had a friendly relationship that also included discussions about life and future plans. We might conclude that establishing a master-student relationship in India is value-based, in the sense that the relationship can be formed only if the master decides that the student seeking his teaching is actually suitable. It means that the personal character, values and aims of a student need to be previously assessed and approved by the master.

When characterizing the Shaolin Temple's education as traditional, the students observed that no matter what you had invested to come, the money and time, and what you had announced as the reason for coming, the master would only respond to your motivation and your hard work over a longer time. It is not necessary for the master to accommodate all the students' wishes and expectations. The Temple's renowned name allows the masters to stick to their principles. After all, the students come to the Temple because the traditional Chinese teaching conceptions are still maintained.

The approach the masters have towards an individual and the group, which is seen as the major point of difference in pedagogic approaches at the Shaolin Temple and at home, is described by the students in a variety of ways. Beside one 
student who said that the masters were identical with an individual and the group, a majority noticed particular differences, such as: "The masters approach the group in a firm but understanding way"; "We always train individually, but the students can help each other"; "They have more patience with the individuals"; "The attention is directed towards the group rather than to the individuals". In general, the students concluded that the masters were stricter with the group than with the individuals. However, some would have liked the masters to be stricter with them because that would make them feel that they were experiencing a real Shaolin training. One student noted that the masters were stricter with the Chinese students because they represented Shaolin while the only thing they strictly asked the foreigners to follow during the trainings was the basic rules of discipline.

The language barrier between the masters, most of whom speak only Chinese, and the students, of whom a great majority do not speak a word of Chinese, was addressed by the students as an important issue. Some of the most illustrative responses were: "Sometimes the masters try to teach something but we don't understand ... there is a language barrier"; "Our eyes must get used to seeing the moves and understanding this perfection"; "The students need to ask if they want to learn something new".

\section{Discussion}

\section{Shaolin master's signature}

The foreign students' characterizations of the Shaolin kungfu program and the Shaolin masters illustrate how they feel and theorize this martial arts practice. The tricky part for the foreigners is to discern different aspects of a master's habitus, i.e., which characteristics are personal, which ones are common for all the Shaolin kungfu masters, and which ones can be attributed to the Chinese culture. Nevertheless, the masters' impeccable discipline and adherence to the Shaolin Temple's rules is perceived as the most representative aspect of the Shaolin culture. It rarely happens that a particular master's teaching method is generalized as the Shaolin master signature. ${ }^{11}$ Instead, the students mostly perceive that the Shaolin culture, being deeply embedded in a master's body-heart, is his most prominent signature.

The master's degree of strictness was perceived differently by the students depending on what kind of discipline they had been used to in their families and daily life, and on the kinds of relationships they had had with their masters/trainers at home. In other words, their perceptions were influenced by their individual habitus (Bourdieu 1972, 72; Delamont and Stephens 2008, 59).

The students come from very different cultural backgrounds, and are of varied educational level, diverse professional orientations and age. Most importantly, their experience in physical activity goes from none to professional. A majority of

\footnotetext{
${ }^{11}$ We here rely on the concept of signature of the moving body as developed by Ophir $(2016,187)$, which she defines as: "the unique teaching style of each teacher - his/her singular way of moving, teaching, and experiencing through a given physical-cultural-historical framework".
} 
students come from Europe and North America, and are used to a particular relationship between the master and the student(s), which they cannot find in the Shaolin Temple. Some of the Western students find it interesting as a different experience and are very excited to have the opportunity to live the real traditional way of teaching while the others ascribe the masters' behavior to a lack of enthusiasm or inadequate organization of the training sessions. The stances of the Indian students, on the other hand, indicate that the master-student relationship needs to encompass a more holistic perspective of the student's progress. The martial arts practice is something that should help in strengthening individual character and will in order to bring success in future endeavors. In contrast to the Western teaching approach, which is limited to the practice itself, the Indian master's teachings and advice can also be oriented to the student's decision making in different aspects of life, i.e., professional career, social and cultural values, and philosophical understanding of life.

The students who perceived their stay in the Shaolin Temple as a cultural experience and tried to approach the Temple culture in its entirety (or at least to see the martial arts related with its religious context) were more eager and able to understand the present-day Shaolin kungfu practice and its role for the Temple's community.

At this point, an important question arises: to what extent do the students actually explore the cultural context of the martial arts practice they are willing to undertake? Bowman $(2016,565)$ states that, surprisingly, most of the martial arts students he encountered do not know much about the history of the practice. Our research experience suggests that it is not only the history that helps one understand the integrality of the martial arts practice, but also the insights into the whole culture of the practice, both its ideological grounding and its individual and social uses. Only by acquiring this kind of knowledge, the practitioner's own cultural background gets to intermingle with the Shaolin culture, and he/she obtains the opportunity to become enriched by the martial arts studied. Besides, the students tirelessly aspire to grasp the essence of the Shaolin culture from the master's moving body, as if it was something possible to extract, grasp and appropriate. In our view, the teaching body (Ophir 2016) in this case presupposes that the body itself is an entity dynamically embodying the Shaolin kungfu, ready for manifesting all or any of the Shaolin culture aspects. It is our contention that the master's body expression is as tangible as the Shaolin kungfu essence can become. Watching the masters is like reaching to grasp the Shaolin kungfu, being on the verge of recognizing it as an entity, as something that can be perceived, grasped and defined. In doing this, we tend to try to isolate kungfu from itself, to define it as something separate from the body. The dynamic embodiment (Williams 1982, 1991; Farnell 1994, 1999, 2012; Varela 2003) allows us to understand that as much as the body is infused with the Shaolin kungfu, so much is each its performance infused with the characteristics of the particular body performing it. Trying to isolate and extract the knowledge by analyzing the body techniques and movement structure and make of it a separate entity using semantic analysis surely results in a miscomprehension of the nature of embodied knowledge and the learning process. In fact, we may say 
that what can be extracted and transferred from one person to another is the essence of the Shaolin kungfu practice.

The status of Shaolin kungfu as a national intangible cultural heritage ${ }^{12}$ determines not only the way it is preserved by the Shaolin Temple's community members but also the way it is presented and shared with international public. On one hand, the Temple keeps the ancient written sources of the Shaolin kungfu in its library and publishes novel written and visual material on related themes. Since most foreigners who come to the Temple do not read Chinese, these sources stay inaccessible to them. On the other hand, the masters are the keepers of the Shaolin kungfu heritage. A master's body is a living treasury of the theory of Shaolin movement, self-defense and self-preservation techniques. This knowledge and skills are transmitted through the master-student relationship. If this relationship is limited by a lack of language skills and time, which is the situation most of the students find themselves in, it is obvious that they can only learn a limited part of what the masters can offer. The students who were more acquainted with the Temple's cultural context were more successful in understanding the master-student relationship and the masters' teaching methods than the students who had come concentrated only on kungfu. Even the students who come more than once tend to return only for a particular purpose and sometimes end their stay not entirely satisfied because things did not go according to their plan.

\section{Relationship between learning kungfu and self-development}

Our research has shown that two aspects of the Shaolin kungfu practice, the selfdefense and health improvement, represent the main motivations of the foreign students for coming to study at the Shaolin Temple. The students, who perceive the Shaolin kungfu within the scope of self-defense, trust the efficiency of the martial arts techniques due to the long-lasting tradition and popularity of the practice. From this perspective, kungfu brings the individual a feeling of security. Due to the intensity of exercise requiring a whole-body effort, it also contributes to the overall fitness of a performer. The students who primarily recognize the selfcultivation aspect of the Shaolin kungfu strongly believe that its greatest value is a positive contribution to their mental and physical health. Apart from the benefits that all physical activities share, the Shaolin kungfu is conceived to have a special value for personal well-being because of its relation to Chan Buddhism. As they mostly perceive the Chan practice as connected to meditation, there is almost a common understanding that the kungfu practice should cultivate a meditation like state of mind, being calm and focused. Thus, the Shaolin kungfu should help the practitioner control his/her mind and stay peaceful, which further helps in stress relief and both mental and physical disease prevention. The other benefits usually assigned to the practice of meditation that are expected to apply to the Shaolin kungfu are: concentration, clarity of mind and self-discipline improvement, which

\footnotetext{
${ }^{12}$ The Shaolin kungfu was pronounced the National intangible cultural heritage of China in 2006 (www. ihchina.cn/project_details/13786/).
} 
in addition helps an individual in establishing and maintaining a healthy life style and optimal work efficiency.

Influence of the Shaolin Temple experience on the foreign student's habitus

The foreign students' responses indicate that their experiences of the Shaolin Temple's educational process and the surrounding cultural environment have made a certain impact on their personal habitus. In other words, it may be said that a new layer of valuable intercultural experience has been added to their "system of durable, transposable dispositions" (Bourdieu 1972, 72) or to their "state of mind and a bodily state of being" (Delamont and Stephens 2008, 59).

Nonetheless, analysis of the degree of socialization that the students exposed themselves to during their stay at the Shaolin Temple was problematic on the following points. First, the time the students spent within the Temple's community was in most cases not enough for them to undergo any deeper processes of socialization. Second, the students did not make a true effort to prepare for immersing into the community (learning the Chinese language, reading about the Shaolin culture, requesting information from the Temple about its daily life, etc.) before coming to the Temple, and once they found themselves in the Temple, it seemed like a very difficult task. Consequently, the foreigners stayed among themselves and the needed information was provided by a few individuals who either spoke Chinese and/or had spent a longer time in the Temple. That information was mostly based on the narrow personal perspectives of the more experienced students and could not provide an actual understanding of the essentials of the Shaolin culture. Even though some students spent several months in the Temple, they were actually always in a balloon of ignorance, which did not allow a direct experience of the culture and personal development in the Temple.

Third, because of the popularity of the Shaolin Temple and, more generally, the Chinese martial arts, students come to the Temple with ideas inspired by the popular culture (Nikitina and Furuoka 2013; Bowman 2019). Since it was the popularity of the Shaolin kungfu that actually inspired most of them to come to the Temple in the first place, they had certain expectations upon the arrival. Therefore, the first students' steps in organizing their time and setting the personal goals in the Temple were always based on these expectations. This way, they limit their immersion into the local culture from the beginning and never actually give themselves space to experience the Shaolin culture.

The fourth and last point is that, in order for one to feel immersed in a community and to socialize, it is necessary to have a minimum of freedom of communication with the community members. In this case, the openness of interaction is very difficult to establish, firstly, because of the language barrier, secondly, because of the Temple's rules and way of life (which are different for the monastic community and foreign students), and thirdly, because the Temple is also a popular Chinese tourist cultural and scenic area, visited by thousands of people every day, who come in-between and to a certain extent hinder the mentioned social contacts.

Being aware of these four problems, which are obstacles for a deeper socialization of the students in the Shaolin Temple's community, may help in 
developing new strategies for raising the intercultural kungfu pedagogies to a higher level.

\section{Conclusions}

Our overall research has shown that the foreign students' perceptions of the Shaolin masters' teaching method were fairly consistent. The students perceive the masters as an embodiment of the Shaolin culture, and as the living examples of interpenetration of the Chan Buddhist teachings and the martial arts practice. A master's body is conceived as a living treasury of the theory of Shaolin movement, self-preservation and self-cultivation techniques. The students also noted that, in traditional settings such as the Shaolin Temple, the knowledge and skills are transmitted through the master-student relationship. The traditional robe the masters wear, their firm voice and authoritative demeanor impressed the students and seemed to be enough to provide appropriate discipline in the classes. However, the personal signature of the masters' teaching method is rarely understood as part of their individual character, and is instead mostly attributed to the characteristics of the traditional Temple's education or, more generally, of the Chinese educational culture.

The students also noticed that in all the activities organized at the Shaolin Temple, including the kungfu classes, the attention was directed towards their whole group, and that the individual attention was hard to get. The masters were also said to perceive the role of kungfu in the students' lives to be light, mostly as one of a hobby or a cultural experience. Consequently, they saw their pedagogic role in teaching the elements of Shaolin kungfu in a broader cultural context. That also made the training discipline for the students somewhat looser and its content more flexible. In addition, it cannot pass unnoticed that a majority of students had very scarce prior knowledge about any of the essential elements of Shaolin culture, such as Chan Buddhism, Shaolin kungfu, or the rules of daily monastic life. They also expected to acquire the basic knowledge on the Temple in a relatively short time without being able to speak the Chinese language.

The students made comparisons between the approaches to teaching in the Shaolin Temple, where one needed to earn the master's attention through selfeffort, and the teaching approaches in the West, where the training content and the teacher's readiness to instruct were determined by the pre-established conditions. Also, the traditional kungfu, for which the Temple is famed, was commonly given more praise and attributed more value to than the modernized martial arts forms popularized around the world today through performances and competitions. The traditional kungfu gained kind of a sacred appeal with the students.

The positive influence of the Shaolin kungfu on the students seemed to be mostly centered on the physical and mental health improvements, bringing more calm to one's mind as well as developing the strength of will. Lastly, training kungfu was considered to bring more self-assurance thanks to its defensive potential. 
Due to the facts that a great majority of the students' time in and around the Shaolin Temple was limited to a maximum of a few months and the contacts with the local community were minimized due to a lack linguistic proficiency, the development of a new layer of their habitus took place in a limited manner. However, the time spent in the Temple represented for the students an experience of cultural exchange, which motivated those individuals of different cultural and religious backgrounds to discover the ways of self-cultivation and self-discipline, and to appreciate, at least partially, the traditional Chinese heritage.

The road from arriving to the Shaolin Temple to actually reaching a point at which a student feels that he/she has understood the basic aspects of the Shaolin culture requires a lot of patience and determination. The students' program is organized in the way that one has the support necessary to learn and progress, but, without any question, he/she needs to possess personal motivation and persistence in learning, and, most importantly, in practicing continuously the kungfu skills. In order to develop his/her own kungfu, one should rely on no one but himself/herself. Even though the Shaolin kungfu has been passed on for centuries through dozens of generations through tireless trainings, its essence seems to be embedded in personal development. The way this traditional knowledge is offered to the students and practitioners from all around the world seems to be an example of a specific kind of intercultural pedagogy.

We hope that this study will contribute to anthropological research in the field of martial arts with the following three points. Firstly, we have analyzed the students' experiences of the Shaolin Kungfu training in an authentic cultural context, in the Shaolin Temple. Secondly, the study has shown a creative potential of integration of three theoretical approaches - the anthropological theory of education, the embodiment theories, and the theory of practice. Thirdly, these theories combined with the personal experience of thick participation and the analyses of interviews with the students, have led to the concept of intercultural martial arts pedagogies and its application in a Chan Buddhist setting.

Another contribution of this research should be in overcoming the dichotomies regarding martial arts present in anthropological literature, where they are often analyzed according to their seemingly distinct social functions. Instead of separating and categorizing martial arts as sport, performing art, health practice, or selfcultivation spiritual practice, they should be treated holistically, as a complex socio-cultural phenomenon.

Acknowledgements I am most grateful to the Abbot of the Shaolin Temple, his Holiness Shi Yongxin, and the whole Shaolin Temple monastic community for enabling this research as well as to the participants in the Shaolin Temple foreign students' kungfu program, who agreed to be my respondents. I would like to thank Prof. Bojan Žikić, Prof. Miloš Milenković, and Prof. Vesna Vučinić, from the University of Belgrade, for numerous discussions during this research.

\section{Author's contributions}

Individual authorship. The author(s) read and approved the final manuscript. 


\section{Funding}

Non applicable.

\section{Availability of data and materials}

The data used and analyzed in the study are available from the author on reasonable request.

\section{Ethics approval and consent to participate}

The research has been carried out within the ethical framework defined by the Department of Ethnology and Anthropology, Faculty of Philosophy, University of Belgrade, Serbia.

\section{Consent for publication}

Not applicable (the text does not contain any individual person's data in any form).

\section{Competing interests}

The author declares that she has no competing interests.

\section{References}

Bernard, Russel H. 2006. Research methods in anthropology: qualitative and quantitative approaches. Landham: AltaMira Press.

Besnier, Niko, and Susan Brownell. 2012. Sport, modernity, and the body. Annual Review of Anthropology 41: 443-459.

Bloome, D., et al. 2018. Anthropology of education, anthropology in education, and anthropology for education. In The international encyclopedia of anthropology, ed. Hilary Callan. Hoboken: Wiley.

Bourdieu, Pierre. 1972. Esquisse d'une théorie de la pratique: Précédé de trois études d'ethnologie kabyle. Paris: Librairie Droz English edition: Bourdieu, Pierre. 1977. Outline of a Theory of Practice (translated by Richard Nice). Cambridge: Cambridge University Press.

Bourdieu, Pierre. 2002. Habitus. In Habitus: a sense of place, ed. Jean Hillier and Emma Rooksby, 27-34. Aldershot: Ashgate.

Bowman, Paul. 2016. The intimate schoolmaster and the ignorant sifu: poststructuralism, Bruce Lee, and the ignorance of everyday radical pedagogy. Philosophy \& Rhetoric 49 (4 - Special Issue): 549-570 Speech in Revolt: Rancière, Rhetoric, Politics. Project MUSE: muse.jhu.edu/article/638149.

Bowman, Paul. 2019. Deconstructing martial arts. Cardiff: Cardiff University Press.

Brownell, Susan. 1995. Training the body for China: sports in the moral order of the People's Republic. Chicago: University of Chicago Press.

Channon, Alex. 2012. Western men and eastern arts: the significance of eastern martial arts disciplines in British men's narratives of masculinity. Asia Pacific Journal of Sport and Social Science 1 (2-3): 1-22.

Csordas, Thomas. 1990. Embodiment as a paradigm for anthropology. Ethos 18: 5-47.

Csordas, Thomas. 1994. The sacred self: a cultural phenomenology of charismatic healing. Berkeley: University of California Press.

Csordas, Thomas. 2002. Body/meaning/healing. New York: Palgrave Macmillan. 
Delamont, Sara, and Neil Stephens. 2008. Up on the roof: the embodied habitus of Diasporic Capoeira. Cultural Sociology 2: 57-74.

Dreyfus, Hubert L., and Stuart Dreyfus. 1986. Mind over machine: the power of human intuition and expertise in the era of the computer. New York: Free Press.

Farnell, Brenda. 1994. Ethno-graphics and the moving body. Man 29 (4): 929-974.

Farnell, Brenda. 1999. Moving bodies, acting selves. Annual Review of Anthropology 28: 341-373.

Farnell, Brenda. 2012. Dynamic embodiment for social theory: I move therefore I am. London and New York: Routledge.

Farrer, D.S., and John Whalen-Bridge. 2011. Martial arts as embodied knowledge: Asian traditions in a transnational world. Albany: State University of New York Press.

Höfling, Ana Paula. 2006. Resistance from the inside: an analysis of the Jogo de Dentro in Brazilian Capoeira Angola. Journal for the Anthropological Study of Human Movement 14 (2): 83-90 https:// jashm.press.uillinois.edu/14.2/index.html.

Jennings, George, David Brown, and Andrew C. Sparkes. 2010. "It can be a religion if you want": Wing Chun Kung Fu as a secular religion. Ethnography 11 (4): 533-557.

Johnson, A. John. 2017. From technique to way: an investigation into Taekwondo's pedagogical process. Ido Movement for Culture: Journal of Martial Arts Anthropology 17 (4): 3-12. https://doi.org/10.14589/ido. 17.4.2.

Kohoutkova, Jindrisska, Pavol Masaryk, and Zdenko Reguli. 2018. The experience of the state of flow in Brazilian Jiu-Jitsu. IDO Movement for Culture: Journal of Martial Arts Anthropology 18 (3): 1-6 http:// imcjournal.com/index.php/en/volume-xviii-2018/contents-number-3/1357-the-experience-of-the-state-offlow-in-brazilian-jiu-jitsu.

Marchand, Trevor H.J. 2018. Embodied learning. In The international encyclopedia of anthropology, ed. Hilary Callan. Hoboken: Wiley.

Mcdonald, Ian. 2003. Hindu nationalism, cultural spaces, and bodily practices in India. American Behavioral Scientist 46 (11): 1563-1576.

Mullis, C. Eric. 2013. Martial somaesthetics. The Journal of Aesthetic Education 47 (3): 96-115.

Nikitina, Larisa, and Fumitaka Furuoka. 2013. "Dragon, kungfu and Jackie Chen...": stereotypes about China held by Malaysian students. Trames 17 (2): 175-195. https://doi.org/10.3176/tr.2013.2.05.

Ophir, Hodel. 2016. The signature of the moving body: agency and embodied education ideologies of dance teachers. Anthropology and Education Quarterly 47 (2): 186-202.

Samudra, Jaida Kim. 2008. Memory in our body: thick participation and the translation of kinesthetic experience. American Ethnologist 35 (4): 665-681.

Shahar, Meir. 2008. The Shaolin monastery: history, religion, and the Chinese martial arts. Honolulu: University of Hawai'i Press.

Shi, Yongxin - 释永信. 2014. Shaolin gongfu - 少林功夫. Beijing - 北京: Jin cheng chubanshe - 金城出 版社 (Gold Wall Press). English edition: 2020. Shaolin Kungfu (translated by Ma Lianzhen and Wang Qiong). Beijing. Lighthouse Publishing and People \& Tangel Publishing House.

Spindler, George. 2000. Previews. In Fifty years of anthropology and education 1950-2000: a spindler anthology, ed. George Spindler, 25-48. Mahwah: Lawrence Erlbaum Associates.

Varela, Charles R. 2003. Reaching for a paradigm: dynamic embodiment. The Journal of the Anthropological Study of Human Movement 12 (4): 125-131.

Vučinić Nešković, Vesna. 2013. Metodologija terenskog istraživanja u antropologiji: od normativnog do iskustvenog (Methodology of anthropological research: from the normative to the experiential). Belgrade: Serbian Genealogical Center and Faculty of Philosophy, University of Belgrade.

Wacquant, Loic J.D. 2004. Body \& soul: notebooks of an apprentice boxer. Oxford: Oxford University Press.

Williams, Drid. 1982. Semasiology: a semantic anthropologists view of human movements and actions. In Semantic anthropology, ed. David Parkin, 161-182. New York: Academic.

Williams, Drid. 1991. Ten lectures on theories of the dance. Metuchen: Scarecrow Press.

\section{Publisher's Note}

Springer Nature remains neutral with regard to jurisdictional claims in published maps and institutional affiliations. 